Conference Proceedings Paper

\title{
Increasing the Efficiency of Vacuum Belt Filter in Gol-E-Gohar iron ore concentrate production by adding surfactants
}

\author{
Ahmad Azargoon Jahromi ${ }^{1, *}$, Hojat Naderi ${ }^{2}$ and Ali Dehghani ${ }^{3, *}$ \\ 1 Department of Mining and Metallurgical Engineering, Yazd University, Yazd, Iran; \\ ahmad.azargoon@gmail.com \\ 2 Department of Mining and Metallurgical Engineering Yazd University, Yazd, Iran; Naderi@yazd.ac.ir \\ 3 Department of Mining Weir Minerals Europe, Glasgow, United Kingdom; ali.dehg@gmail.com \\ * Correspondence: ahmad.azargoon@gmail.com; Tel: +98-991-380-1400
}

Received: date; Accepted: date; Published: date

\begin{abstract}
In this research, filtration experiments were carried out by four types of surfactants as filter aid. Sodium dodecyl sulfate and sodium lauryl ether sulfate as anionic surfactant (SDS and SLES), Polyethylene glycol as nonionic surfactant (PEG) and Cetyl trimethylammonium bromide as cationic surfactant (CTAB) were used to were used in order to evaluate their effects on moisture reduction of concentrate and improvement filtration process. All of tests were done at the optimal conditions include $60 \mathrm{KPa}$ vacuum pressure, 120 seconds filtration time, 105 microns particle size and $60 \%(\mathrm{w} / \mathrm{w})$ solid content of pulp. results showed that in all of tests, cake moisture decreased by adding surfactants however anionic surfactants SDS and SLES were better than other chemicals. by adding $100 \mathrm{~g} / \mathrm{t}$ SDS and SLES to the pulp, the filter cake moisture content was reduced by $2 \%$. SDS and SLES improves filtration performance by increasing the ratio of throughput to moisture. At the concentration of $100 \mathrm{~g} /$ ton SDS and SLES, the highest throughput and lowest moisture was achieved. Although both of SDS and SLES have similar chemical structure and action, but SLES was selected Due to better solubility in hard water, economic justification and availability.
\end{abstract}

Keywords: Horizontal belt filter, Cake filter, Surfactant, Blain, Vacuum Filtration, Dewatering

\section{Introduction}

In general, the variables affecting the filtration process can be classified into three groups: the technical specifications of the filtration device used (such as the maximum difference between the pressures produced on both sides of the filtration media, filtration time, type of filtration media, device volume, and filtration area), the characteristics of the materials to be filtered (such as the pulp present, pulp temperature, pulp viscosity and specific gravity, pulp $\mathrm{pH}$, particle size, and particle shape), and the type of material used to improve the performance of the filtration process that is called the filtration chemistry (such as the flocculant, coagulant, and filter aid) [1-3].

Patra et al. (2016) have studied and improved dewatering of the iron ore fines by the usage of surfactants. In their primary studies, they found that the main problem with the dewatering process was adherence of the ultra-fine particles to the iron particles. Surfactants improved dewatering by increasing the hydrophobicity. The surfactant cetyl trimethyl ammonium bromide (CTAB) was used 
to neutralize the particle charge. By adding CTAB, the moisture dropped from $12-13 \%$ to $9-10 \%$ [4]. (6)

Castro and Laskowski (2015) have studied the effect of flocculants on flotation of coppermolybdenum ore. The results obtained showed that the flocculant polyacrylamide (PAM) had a negative effect on the recovery. It was also found that the flocculent polyethylene oxide (PEO) was an effective one for molybdenum in a wide range of $\mathrm{pH}$ values but in any case affected the molybdenum flotation efficiency [5].

Fan et al. (2015) have studied the effect of particle properties on the filtration of fine-grained coal pulp and the structure of cake formed. Their studies postulated that the addition of kerosene to the pulp led to an increase in the cake hydrophobicity and a decrease in the moisture content of cake to $4.41 \%$. Addition of the flocculent to the pulp, due to bridging between the particles or neutralizing the particle surface charge, could form large clots so that the filter cake resistance decreased and the permeability increased [6].

Garmsiri and Shirazi (2014) have examined the effect of grain size on the preparation of flocculants. In this work, the effect of the size of solid flocculant particles, grain size reduction, and their solubility with high molecular weight anionic flocculant were studied. The results obtained showed that with smaller particles, less time was required to achieve a high settlement rate. The dissolution heterogeneity decreased due to the presence of gels by filtration. By increasing the grain size, the preparation time of the flocculant increased, and, on the other hand, reducing the amount of coarse grains led to a reduction in the preparation time [7].

Sarkar et al. (2014) have examined a polymeric flocculant based on amylopectin grafted with poly (acrylic acid) (g-AP) for the treatment of a synthetic effluent as well as various industrial wastewaters. The results obtained showed that g-AP could be used as an effective flocculant for removing the suspended silica particles as well as the cationic and anionic colors of aqueous solutions under different $\mathrm{pH}$ conditions [8].

Liu et al. (2014) have examined the effect of an effective eco-friendly cellulose-based flocculant, BPCgPAM, for the treatment of effluent from paper mill waste. results obtained showed that in neutral and acidic conditions, the BPC-gPAM flocculant had a better efficiency than polyacrylamide for the treatment of plant wastewater. The BPC-gPAM flocculant is a suitable option for usage in industries due to its biodegradability and low cost, and removal of cadmium particles from paper plant waste [9].

Wang et al. (2014) have studied the characterization of the dewatering process of activated sludge assisted by cationic surfactants. During the experiments, it was found that surfactant cetyl trimethyl ammonium bromide (CTAB) was more effective than the surfactant dodecyl trimethyl ammonium bromide (DTAB) for the release of water bonded to solid particles. The surfactant significantly increased the dewatering efficiency of the pulp due to reduction in the resistance and moisture [10]. Lihong et al. (2011) have studied the enhancement of the efficiency of the filtration process with filter aids such as diatomaceous earth and wood pulp cellulose. Investigations showed that by adding filter aids, the filtration rate increased and the moisture content of cake decreased due to changes in the structure, porosity, compressibility, hydraulic resistance, and cake permeability [11]. (6)

Wang et al. (2009) have examined the effect of a novel flocculant with a high water-solubility (Chitosan-g-PDMC) on the factory effluent. The studies have shown that Chitosan-g-PDMC has an excellent flocculation capacity and that the flocculation efficiency is much better than polyacrylamide [12].

The aim of this work was to investigate the effect of different surfactants on the filtration responses such as the cake moisture content, cake formation time, water recovery and throughput. The vacuum top-feed method was applied for dewatering the magnetite concentrate.

\section{Materials and Methods}

The sample used for the filtration experiments was originated from the line 5 of Gol-E-Gohar mining and industrial Complex. The sampling was performed at 1 hour intervals after the beginning of each 
shift and during 20 days from the concentrate of final LIMS (filter input). At the end of each work day, the samples were transferred to the mineral processing laboratory of the Gol-E- Gohar Iron Ore and Steel Research Institute, and were packed and dried after calculating their solid percent. The line 5 of concentrator plant has about 6000-ton production per day, and its concentrate is entered into the HPGR for increasing blain. The optimal performance of the horizontal vacuum belt filter bye produce dry concentrate is led to make suitable feed with $1800 \mathrm{~g} / \mathrm{cm} 2$ blain by HPGR for pelletizing plants. In this research, four surfactants were used in order to evaluate the filtration experiments. The chemicals used in the experiments were Sodium dodecyl sulfate and sodium lauryl ether sulfate as anionic surfactant (SDS and SLES), Polyethylene glycol as nonionic surfactant (PEG) and Cetyl trimethylammonium bromide as cationic surfactant (CTAB). Absorption of the surfactant in the gasliquid interface reduces the surface tension of the liquid and also increases the hydrophobicity of the solid particles.

Filter aids are materials that, by forming a porous layer on the filter media, improve the flow of water from the media. Dissolving filter aids are nonpolymeric compounds and include one or more hydrophiles (sulfonate, carboxylate, ethoxylate) and hydrophobic groups, and usually have a long chain of hydrocarbons $[13,14]$.

The filter aid reduces the compressibility and increases the porosity of the cake, which leads to a decrease in the specific cake resistance and an increase in the cake formation rate and improving the dewatering condition. At higher concentrations of the filter aid in the liquid phase, due to the effect of its molecular weight, the increase in the viscosity of the pulp, the drop in the cake formation rate, and the increase in the moisture content of the filter cake were observed. Obviously, a higher viscosity is created by the filter aid with a higher molecular weight so in this research, these surfactants used as filter aids.

The vacuum filtration experiment was performed via the vacuum top-feed leaf method using a Buchner funnel, a graduated cylinder, and a vacuum manufacturing system (Figure 12 in appendix A). The purpose of performing the experiment with this method was to evaluate the filtration responses such as cake moisture content, cake formation time and water recovery were considered. Vacuum was applied to the filtrate flask by means of a vacuum pump, and its level measured by a vacuum gage and regulated to $60 \mathrm{KPa}$ by using a control valve. Each test was performed by reconstituting the iron ore concentrate slurry with water to give a suspension containing $60 \%$ solids by weight. All the surfactants investigated in this study were water soluble and were prepared by dissolving $1 \mathrm{~g}$ of the reagent in $500 \mathrm{~mL}$ of distilled water. Surfactant with appropriate dose was added to the slurry and mixed well for 2 minutes. Then the slurry was poured to the Buchner funnel and the vacuum was applied. Filtration was stopped 120 second after cake formation time (the time that disappearance of water from the upper surface of the filter cake). At the end of each test, the moist cake was placed in a dryer for $24 \mathrm{~h}$ at a temperature of $90^{\circ} \mathrm{C}$. The filtrate volume was measured during the test.

The moisture content bason the wet weight is calculated as bellows: moisture and throughput are commonly used to evaluate filtration performance. The moisture content of the cake was calculated using Equation (1), where $\mathrm{M}$ is the weight of the cake. throughput or filter capacity indicates the amount of cake produced per unit area per unit time, usually expressed in tons per hour per square meter. Equation (2) indicates the throughput at which $\mathrm{MD}$ is the weight 
of the dried cake formed on the filter cloth $(\mathrm{kg}), \mathrm{T}$ is the total time of a complete filtration cycle (s), and $\mathrm{A}$ is the surface area of the filter cloth $\left(\mathrm{m}^{2}\right)$. Cake porosity was also calculated from Equation (3) where $V_{P}$ cake porosity, $W_{s}$ and $W_{D}$ are wet and dry cake weight respectively and $D_{W}$ is water density.

$$
\begin{aligned}
& \text { Moisture }=\frac{\mathrm{M}_{\mathrm{wet}}-\mathrm{M}_{\mathrm{dry}}}{\mathrm{M}_{\mathrm{wet}}} * 100 \\
& \text { Throughput }=\frac{\mathrm{M}_{\mathrm{dry}}}{\mathrm{A} \cdot \mathrm{T}} \\
& \mathrm{V}_{\mathrm{P}}=\frac{\mathrm{W}_{\mathrm{S}}-\mathrm{W}_{\mathrm{D}}}{\mathrm{D}_{\mathrm{W}}}
\end{aligned}
$$

\section{Results}

\subsection{Sample characterization study}

The representative sample was analyzed using the X-ray fluorescence (XRF) technique in order to determine the major and minor elements and oxides. The result of XRF analysis showed that $\mathrm{Fe}, \mathrm{FeO}$, $\mathrm{S}$ and $\mathrm{Al}_{2} \mathrm{O}_{3}$ were the major components, and other oxides such as $\mathrm{CaO}, \mathrm{MgO}, \mathrm{Si}_{2} \mathrm{O}$ were the minor components presented in the concentrate sample. The XRF analysis results are presented in Table 1. More than $70 \%$ of the original sample was formed from that $\mathrm{Fe}, \mathrm{Al}_{2} \mathrm{O}_{3}$ and $\mathrm{S}$. Fig. 1 shows sample particle size distribution curve. It can be seen in Fig. 1, the D80 of the sample was $105 \mu \mathrm{m}$.

Table 1. XRF analysis of the concentrate sample prepared from the Gol-E-Gohar concentrate production plant

\begin{tabular}{cccccc}
\hline Component & $\mathrm{Fe}$ & $\mathrm{FeO}$ & $\mathrm{Al2O} 3$ & $\mathrm{SiO} 2$ & $\mathrm{TiO}_{2}$ \\
$\%$ & 69 & 26 & 1.31 & 0.26 & 0.04 \\
\hline Component & $\mathrm{CaO}$ & $\mathrm{MgO}$ & $\mathrm{S}$ & $\mathrm{P}$ & L.O.I \\
$\%$ & 0.31 & 0.22 & 0.3 & 0.05 & 2.51 \\
\hline
\end{tabular}

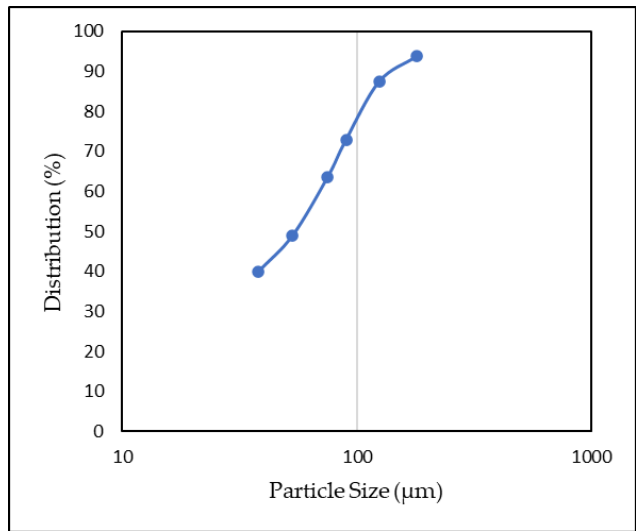


Figure 1. Particle size distribution of the sample

\subsection{Effect of surfactants on moisture}

The effect of surfactants on moisture is shown in Figure 2. In the case of no additive, the moisture content of the filter cake was \%9.2. At a dose of $50 \mathrm{~g} / \mathrm{ton}$, all of surfactants reduced moisture except PEG. In this dosage, SLES caused the greatest decrease in moisture and reached $7 \%$. At a dose of $100 \mathrm{~g} /$ ton SDS and SLES, the moisture content of the concentrate was the lower than others and that was \%7.2. At a dose of $150 \mathrm{~g} / \mathrm{ton}$, increasing the surfactant concentration increased the moisture. Lowest moisture in this dosage was value of \%7.7 obtained for SDS and SLES.

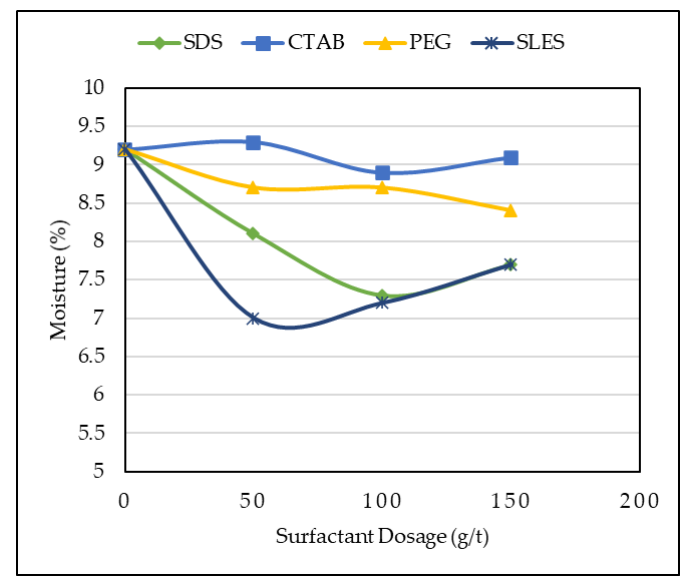

Figure 2. Effect of surfactants on moisture

\subsection{Effect of surfactants on water recovery}

the recovery of water for each dosage of surfactants was calculated in which results are presented in Figure 3-5. As it can be seen in the Figure 5, by increasing the surfactant concentration of 50-150 g/t, water recovery was increased. the maximum water recovery was obtained 375 and $365 \mathrm{ml}$ for SDS and SLES as $150 \mathrm{~g} / \mathrm{t}$ dosage. Figures 3-5 shows the amount of water recovery for each of the surfactants at concentrations of 50,100 and $150 \mathrm{~g} / \mathrm{ton}$. Charts have two parts. Linear section and curved section. The linear part of the graph is related to the water recovery rate from the beginning of filtration to the time of cake formation. As the slope of the graph increases, the speed of cake formation increases.After the cake is formed, the rate of water recovery is reduced and the filtration process continues for 120 seconds.

Water recovery indicates the amount of water separated from the suspension. But this factor is not enough to evaluate the filtration performance, and along with factors such as cake formation time and filter volume at the moment of cake forming can give us more accurate information to evaluate the effects of surfactants. 


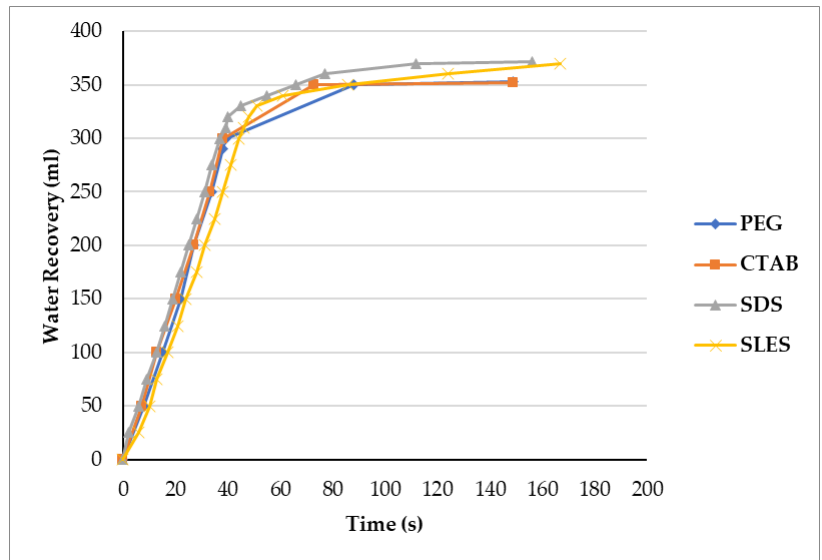

Figure 3. Effect of surfactants on water recovery at $50 \mathrm{~g} / \mathrm{t}$ dosage

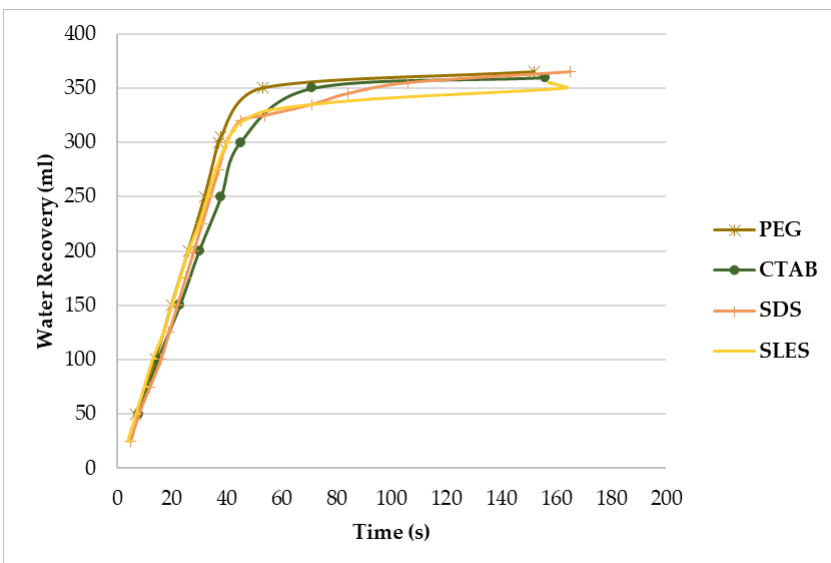

Figure 4. Effect of surfactants on water recovery at $100 \mathrm{~g} / \mathrm{t}$ dosage

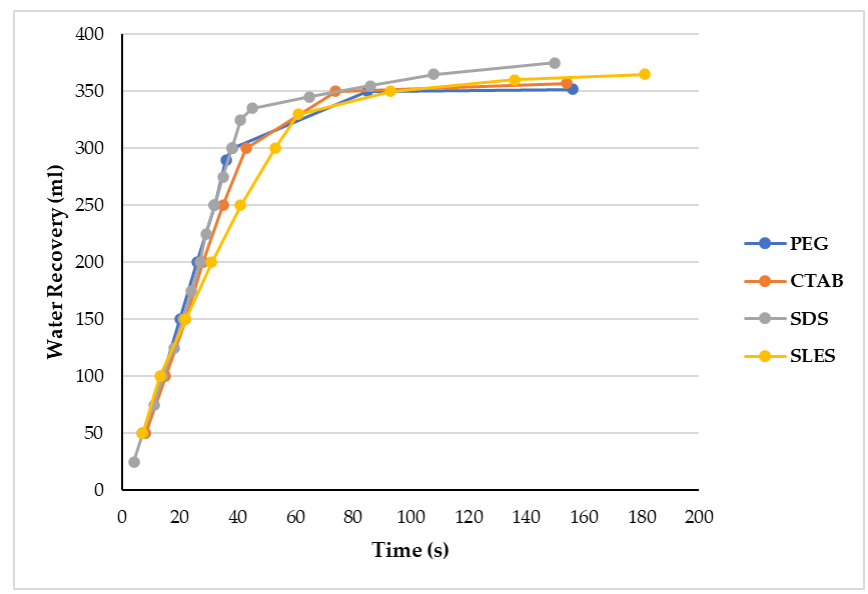

Figure 5. Effect of surfactants on water recovery at $150 \mathrm{~g} / \mathrm{t}$ dosage

\subsection{Effect of surfactants on cake formation time}

Figure 6 shows the cake formation time for surfactants in different doses. Cake forming time without additive was 36 seconds. In all dosage of additive, cake formation time was increased. At concentrations of 50,100 and $150 \mathrm{~g} / \mathrm{ton}$, the minimum cake formation time was for adding PEG. As 
the dosage increased, the cake formation time increases. However, this factor is one of several factors to evaluate filtration performance. SLES at a dose of $150 \mathrm{~g} /$ ton had the longest cake formation time.

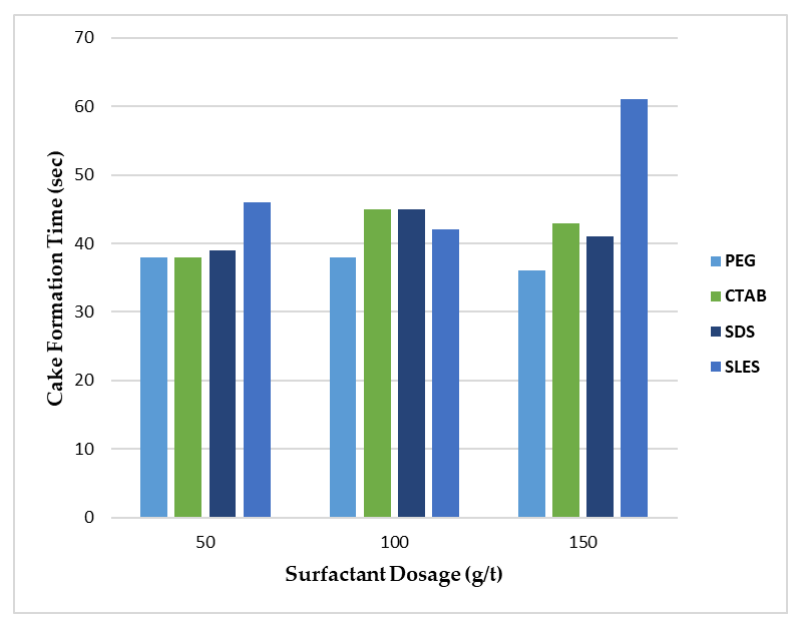

Figure 6. Effect of surfactants on cake formation time at different dosage

\subsection{1. volume filtrate at the moment of formation cake}

Figure 7 shows the volume of filtrate at the time of cake formation for different doses of surfactants. In the case of no additive, the volume of filtrate was $285 \mathrm{ml}$. By adding surfactant at all concentrations, the filtrate volume at the moment of cake formation increased. At dose 100, the maximum volume was SDS. The highest volumes were 330 and 325 for surfactants SLES and SDS, respectively, at a dose of $150 \mathrm{~g} / \mathrm{ton}$.

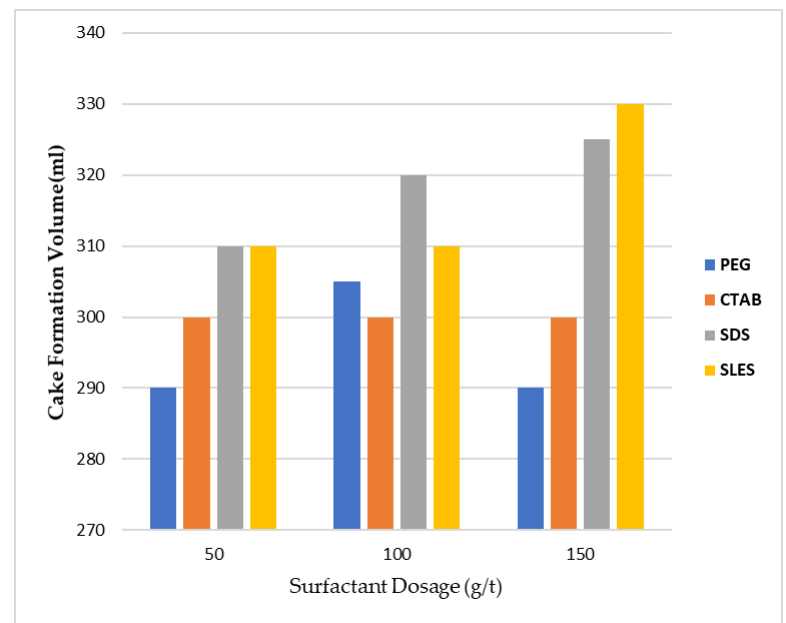

Figure 7. Effect of surfactants on filtrate volume at the moment of formation cake in different dosage

\subsection{Effect of surfactants on throughput}

Throughput is the amount of fluid that will pass through a filter before the filter blocks or the flow rate is reduced to a point that is unacceptable. throughput or filter capacity indicates the amount of cake produced per area per time. In this research throughput expressed in $\mathrm{Kg} / \mathrm{m}^{2} . \mathrm{h}$ 
Figure 8 shows the power for surfactants at different concentrations. The amount of throughput without additive was equal to $962 \mathrm{Kg} / \mathrm{m}^{2}$.h Which is marked in the diagram with a dashed line. The maximum throughput was obtained by adding $50 \mathrm{~g} /$ ton of PEG. At a dose of $100 \mathrm{~g} / \mathrm{ton}$, the throughput for all surfactants had a decreasing trend except SLES. At a concentration of $150 \mathrm{~g} / \mathrm{ton}$, the highest throughput was obtained by adding SDS.

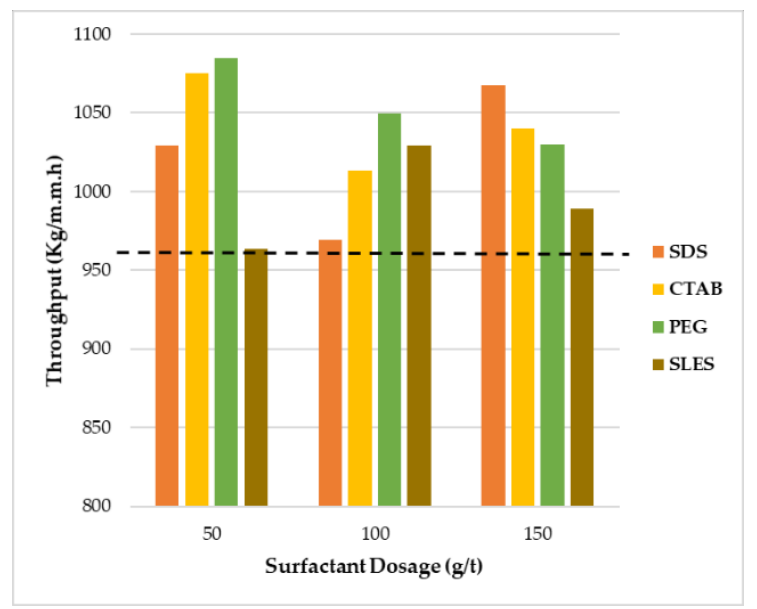

Figure 8. Effect of surfactants on throughput at different dosage

\section{Discussion}

\section{- Moisture}

Surfactants increase the contact angle between liquid and solid particle. Increasing the contact angle increases the particle's hydrophobicity. Therefore, the capillary forces are reduced and the surface tension of the water is reduced. The length of the hydrocarbon chain usually determines the relative hydrophobicity of the surfactants. Therefore, the use of surfactants with longer hydrocarbon chains causes more hydrophobicity and improves filtration performance. $[15,16]$.

The zeta potential of magnetite is zero at $\mathrm{pH}=5.7$ and negative at higher. In use of SDS, as long as the sulfate groups have a negative charge, the two mineral surfaces repel each other and the repulsive effect increases. But due to the absorption of water in hydrophilic groups, the retention of moisture by the mineral surface gradually increases. In the presence of SDS, the isoelectric point of the magnetite is lowest. At natural $\mathrm{pH}$, interionic repulsive forces dominate the SDS, which has a high hydrodynamic radius thus a starch chain is produced so the adsorption factor is more due to the bridging mechanism between the particles.

The main mechanism of adsorption of CTAB on magnetite is charge neutralization. This is due to the positive charge of $C T A B$ and the negative charge of the magnetite surface of SDS and PEG surfactants is often bridging. in CTAB the adsorption mechanism is interaction of electrostatic and neutral loads prevails [17]. So based on the figure 2 It can be concluded that surfactants SDS and SLES by the mentioned mechanism causes hydrophobicity of particles and as a result, achieves the lowest moisture content.

\section{- Moisture vs. Cake formation time vs. Filtrate volume}


At the time of cake formation, two factors are important. Time and volume of filtrate. The shorter the cake formation time, the higher the cake production per unit time and throughput. In cases where the final moisture is not important, this factor affects the production capacity of the plant.

The volume of filtrate at the time of cake formation determines the final moisture content of the concentrate. Therefore, in cases where the final moisture of the product is important, this factor is very effective. Therefore, in order to maintain the balance between production capacity and final moisture, a surfactant should be selected for which the cake formation time is the shortest and the filtered volume is the highest.

According to Figure 2, the average moisture in three dosage for PEG, CTAB, SDS and SLES surfactants are 8.6, 9.1, 7.7 and 7.3 respectively.

According to Figure 6, the average cake formation time in three dosage for PEG, CTAB, SDS and SLES surfactants is $37.3,42,41.5$ and 49.5 seconds, respectively.

According to Figure 7 , the average volume of water separated at the cake formation in three dosage for PEG, CTAB, SDS and SLES surfactants is 295, 300, 318 and 316.5 respectively.

Figure 9 Shows the average values of moisture, filtrate volume and cake formation time for each surfactant So it can be concluded that in the presence of SDS, all three factors are in balance however SLES is preferable to SDS because of better solubility in hard water, economic justification and availability.

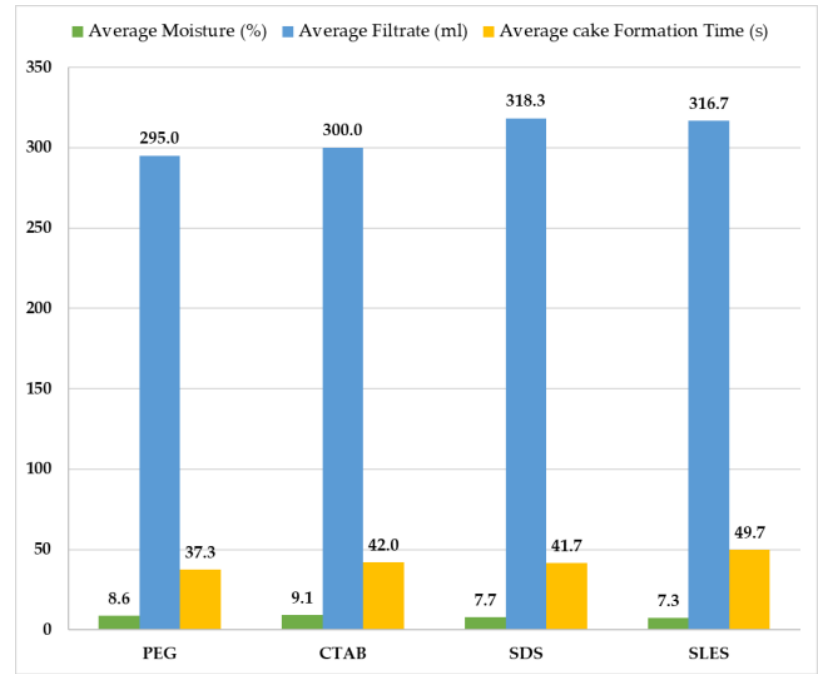

Figure 9. average values of moisture, filtrate volume and cake formation time for each surfactant

\section{- Ratio of throughput to moisture $(\varphi)$}

A ratio of throughput to misture was used to compare the performance of surfactants. Figure 10 shows the Ratio of throughput to moisture for different doses of surfactants. Figure 11 shows the average of this ratio for surfactants. According to Figure 11, the average ratio $(\varphi)$ in three dosage for PEG, CTAB, SDS and SLES surfactants are 123, 115, 132 and 133 respectively.

According to Figure 11, the highest average for this ratio is obtained by adding SLES and SDS respectively. due to the economic superiority of 1 over 2, 1 was chosen as the final surfactant. So SDS and SLES are suitable for filtration of iron concentrate. Although both of them have similar chemical structure and function, but SLES was selected due to better solubility in hard water, economic justification and availability.

The ratio of throughput to moisture of SLES at a concentration of $100 \mathrm{~g} / \mathrm{ton}$ was higher than other dosage, so the concentration of $100 \mathrm{~g} /$ ton was selected as the optimal dosage for the best performance of the filtration process. 


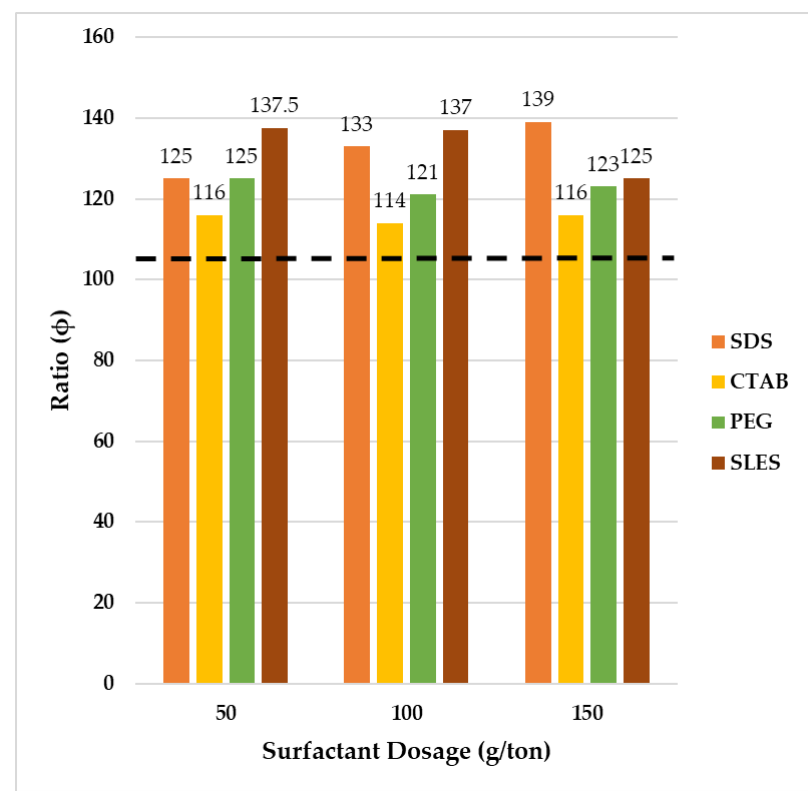

Figure 10. Ratio of throughput to moisture $(\varphi)$ at different dosage

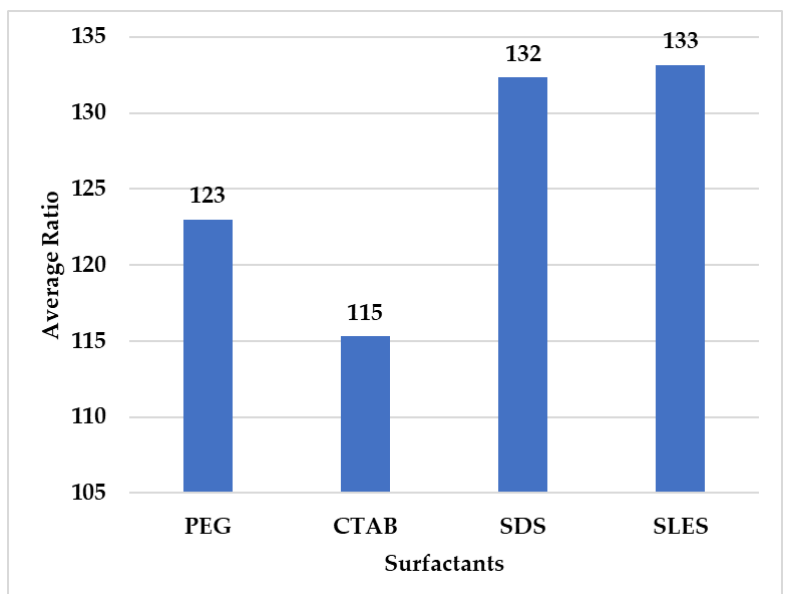

Figure 11. Average ratio of throughput to moisture $(\varphi)$

\section{Conclusions}

results showed that in all of tests, cake moisture decreased by adding surfactants however anionic surfactants SDS and SLES were better than other chemicals. by adding $100 \mathrm{~g} / \mathrm{t} \mathrm{SDS}$ and SLES to the pulp, the filter cake moisture content was reduced by $2 \%$. The SDS and SLES increased filtration efficiency by decreasing cake formation time and increasing the total separated water from pulp, especially at the cake formation time. SDS and SLES improves filtration performance by increasing the ratio of throughput to moisture. At a concentration of $100 \mathrm{~g} /$ ton SDS and SLES, the highest throughput and lowest moisture was achieved and This result was the best compared to other surfactants. So SDS and SLES are suitable for filtration of iron concentrate. Although both of them have similar chemical structure and function, but SLES was selected due to better solubility in hard water, economic justification and availability.

Funding: “This research was funded by GOL-E-GOHAR MINING AND INDUSTRIAL COMPLEX (SIRJAN, IRAN)". 
Acknowledgments: Authors consider it necessary to thank and appreciate all the staff of Gol-E-Gohar Iron Ore and Steel Research Institute and Gol-E-Gohar Mining and Industrial Complex who have sincerely co-operated in conducting this research.

Conflicts of Interest: "The funders had no role in the design of the study; in the collection, analyses, or interpretation of data; in the writing of the manuscript, or in the decision to publish the results".

\section{Appendix A}

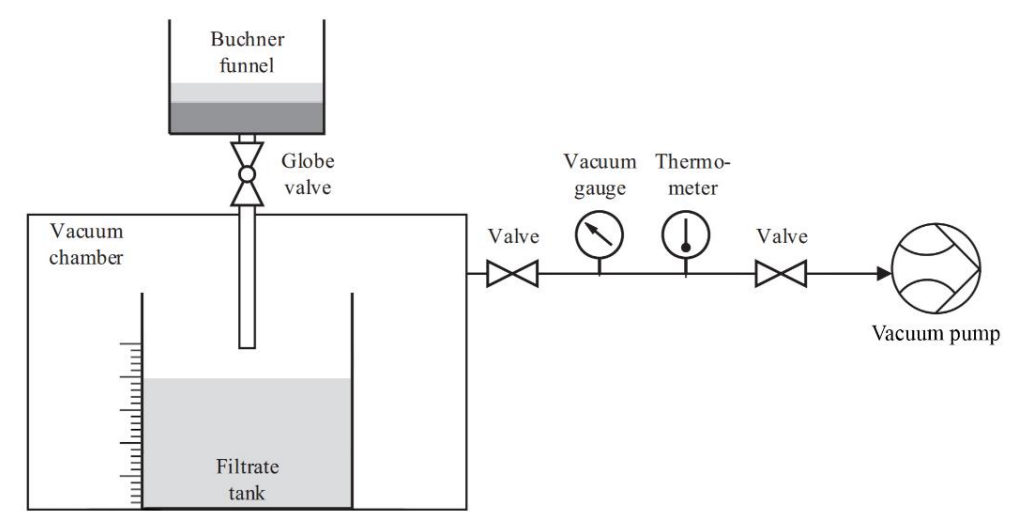

Figure 12. Operational apparatus of filtration process in lab

Table 2. Specifications of the surfactants used in the experiments

\begin{tabular}{lcccc}
\hline Surfactant & Type & Molar mass & $\begin{array}{c}\text { Hydrophobic } \\
\text { group }\end{array}$ & $\begin{array}{c}\text { Hydrophilic } \\
\text { group }\end{array}$ \\
\hline PEG & Nonionic & $3600-4400$ & - & - \\
CTAB & Cationic & 364.4 & & Cetyl \\
SDS & Anionic & 288.4 & Sulfate & Dodecyl \\
SLES & Anionic & 420 & Sulfate & Dodecyl \\
\hline
\end{tabular}




\section{References}

1. Dong, K.J., Zou, R.P., Yang, R.Y., Yu, A.B. and Roach, G. (2009). DEM simulation of cake formation in sedimentation and filtration. Minerals Engineering. 22 (11): 921-930

2. Ni, L.A., Yu, A.B., Lu, G.Q. and Howes, T. (2006). Simulation of the cake formation and growth in cake filtration. Minerals engineering. 19 (10): 1084-1097.

3. Day, A. (2002). Mining Chemicals Handbook, Revised Edition. CYTEC, Horton Printing Company, Meriden, CT

4. Patra, A.S., Makhija, D., Mukherjee, A.K., Tiwari, R., Sahoo, C.R. and Mohanty, B.D. (2016). Improved dewatering of iron ore fines by the use of surfactants. Powder Technology. 287: 43-50.

5. Castro, S. and Laskowski, J.S. (2015). Depressing effect of flocculants on molybdenite flotation. Minerals Engineering. 74: 13-19.

6. Fan, Y., Dong, X. and Li, H. (2015). Dewatering effect of fine coal slurry and filter cake structure based on particle characteristics. Vacuum. 114: 54-57.

7. Garmsiri, M.R. and Shirazi, H.H.A. (2014). The effect of grain size on flocculant preparation. Minerals Engineering. 65: 51-53.

8. Sarkar, A.K., Ghorai, S., Patra, A.S., Mishra, B.K., Mandre, N.R. and Pal, S. (2015). Modified amylopectin based flocculant for the treatment of synthetic effluent and industrial wastewaters. International journal of biological macromolecules. 72: 356-363.

9. Liu, H., Yang, X., Zhang, Y., Zhu, H. and Yao, J. (2014). Flocculation characteristics of polyacrylamide grafted cellulose from Phyllostachys heterocycla: an efficient and eco-friendly flocculant. Water research. 59: 165-171.

10. Wang, L.F., He, D.Q., Tong, Z.H., Li, W.W. and Yu, H.Q. (2014). Characterization of dewatering process of activated sludge assisted by cationic surfactants. Biochemical engineering journal. 91: 174- 178.

11. Lihong, D., Xu, C., Wenping, L. and Qixin, Z. (2011). A study on enhancement of filtration process with filter aids diatomaceous earth and wood pulp cellulose. Chinese Journal of Chemical Engineering. 19(5): 792798.

12. Wang, J.P., Chen, Y.Z., Yuan, S.J., Sheng, G.P. and Yu, H.Q. (2009). Synthesis and characterization of a novel cationic chitosan-based flocculant with a high water-solubility for pulp mill wastewater treatment. Water research. 43(20): 5267-5275.

13. Besra, L., Singh, B.P., Reddy, P.S.R. and Sengupta, D.K. (1998). Influence of surfactants on filter cake parameters during vacuum filtration of flocculated iron ore sludge. Powder technology. 96(3): 240-247.

14. Mackenzie, M., Malhotra, D. and Riggs, W.F. (1986). Chemical Reagents in the mineral Processing Industry. Society of Mineral Engineering. Colorado, USA. 139-145.

15. Singh, B.P., 1997. "The influence of surface phenomena on the dewatering of fine clean coal". Filtration $\mathcal{E}$ separation, 34(2), pp.159-163.

16. Sparks, T., 2012. “Solid-liquid filtration: Understanding filter presses and belt filters". Filtration+ Separation, 49(4), pp.20-24.

17. Patra, A.S., Makhija, D., Mukherjee, A.K., Tiwari, R., Sahoo, C.R. and Mohanty, B.D., 2016. “Improved dewatering of iron ore fines by the use of surfactants". Powder technology, 287, pp.43-50. 